\title{
KARAKTERISTIK DAN ANALISIS DRUG RELATED PROBLEMS (DRPS) PASIEN PENDERITA TUBERKULOSIS DI PUSKESMAS TEMINDUNG SAMARINDA KALIMANTAN TIMUR
}

\author{
Nurul Fauziah, Islamudin Ahmad, Arsyik Ibrahim \\ Labotarium Penelitian dan Pengembangan Kefarmasian FARMAKA TROPIS Fakultas \\ Farmasi, Universitas Mulawarman, Samarinda, Kalimantan Timur \\ email: n.ziah1212@yahoo.com
}

\begin{abstract}
A study concerning the characteristics and Analysis of Drug Related Problems (DRPs) Patients with Tuberculosis Patients in Public Health Center (PHC) Temindung, Samarinda in East Kalimantan. The study was conducted using a prospective approach to the study of data sources in the form of primary data and secondary data. The primary data source is data from interviews with patients and through the provision of questionnaires and secondary data in this research is a Tuberculosis patient medical record data. Data collection was performed by analyzing the accuracy of the DRPs categories of accuracy of drugs, side effects and patient non-compliance. As well as the data recorded in the form of research support patient characteristics are age, sex, and education. Data were analyzed descriptively. Data obtained from patients with male gender $63.6 \%$ and women 36.4. Patient with age $<15$ years $4.5 \%$, aged between $15-50$ years and $68.2 \%$ aged $>50$ years $27.3 \%$. Based on the patient's level of education, no school $9.1 \%$, graduated from elementary school $22.7 \%$, graduated from high school18.2\%, graduated from high school40.1\%, scholar 9.1\%. Incidence of DRPs on drugs interactions 507\%. Tuberculosis patient compliance rate of $81.8 \%$ in PHC Temindung adherent patients and $18.2 \%$ of patients do not comply
\end{abstract}

Keywords: Tuberculosis, Drug Related Problems (DRPs) drugs interactions and patient compliance

\begin{abstract}
ABSTRAK
Telah dilakukan penelitian tentang Karakteristik dan Analisis Drug Related Problems(DRPs) Pasien Penderita Tuberkulosis di Puskesmas Temindung, Samarinda Kalimantan Timur. Penelitian ini dilakukan dengan menggunakan pendekatan prospektif dengan sumber data penelitian berupa data primer dan data sekunder. Sumber data primer adalah data hasil wawancara dengan pasien dan melalui pemberian kuisioner sedangkan data sekunder dalam penelitian ini adalah data rekam medik pasien Tuberkulosis. Pengumpulan data dilakukan dengan menganalisis DRPs kategori interaksi obat dan ketidakpatuhan pasien. Serta dicatat data pendukung penelitian berupa karakteristik pasien yaitu usia, jenis kelamin, dan tingkat pendidikan.Data dianalisis secara deskriptif.Dari data yang diperoleh pasien dengan jenis kelamin laki-laki 63,6\% danperempuan 36,4\%.Pasien yang berusia $<15$ tahun 4,5\%, usia antara 15-50 tahun 68,2\% dan usia $>50$ tahun 27,3\%. Berdasarkan tingkat pendidikan pasien, tidak sekolah 9,1\%,lulus SD 22,7\%,lulus SMP 18,2\%,lulus SMA 40,1\%, sarjana 9,1\%. Kejadian DRPs mengenai interaksi obat 50\%.Tingkat kepatuhan pasien Tuberkulosis di Puskesmas Temindung 81,8\% pasien patuh dan $18,2 \%$ pasien tidak patuh.
\end{abstract}

Kata kunci: Tuberkulosis, Drug Related Problems (DRPs), Interaksi Obat, Kepatuhan pasien. 
PENDAHULUAN

\begin{tabular}{lrrr}
\multicolumn{2}{c}{ Tuberkulosis } & (TB) & adalah \\
penyakit menular & langsung yang \\
disebabkan & oleh & Mycobacterium
\end{tabular} Tuberkulosis, yang sebagian besar $(80 \%)$ menyerang paru-paru.Umumnya Mycobacterium Tuberkulosis menyerang paru dan sebagian kecil organ tubuh lain(DepKes, 2005).

Tuberkulosis (TB) masih merupakan masalah kesehatan baik di Indonesia maupun di dunia serta muncul ke permukaan sebagai penyebab utama kematian.Saat ini TB telah menjadi ancaman global.Penyakit ini banyak menyerang golongan umur produktif antara 15-50 tahun.

Peningkatan jumlah penderita TB disebabkan oleh berbagai faktor, yakni kurangnya tingkat kepatuhan penderita untuk berobat dan meminum obat, timbulnya resistensi ganda, kurangnya daya tahan hospesterhadap mikobakteria, berkurangnya daya bakterisid obat yang ada, meningkatnya kasus HIV/AIDS dan krisis ekonomi. Meskipun berbagai upaya dilakukan oleh pemerintah, namun tanpa peran serta masyarakat tentunya tidak akan dicapai hasil yang optimal karena TB tidak hanya masalah kesehatan namun juga merupakan masalah sosial. Keberhasilan penanggulangan TB sangat bergantung pada tingkat kesadaran dan partisipasi masyarakat (DepKes RI, 2005).

Walaupun di Indonesia telah banyak kemajuan yang diperoleh, yakni pencapaian penemuan kasus baru 51,6 \% dari target global $70 \%$ dibandingkan pencapaian $20 \%$ pada tahun 2002 dan 37 $\%$ pada tahun 2003, juga penyediaan obat-obat anti TB yang dijamin oleh pemerintah untuk sarana pelayanan kesehatan pemerintah mencukupi kebutuhan prakiraan kasus di seluruh Indonesia, TB tetap belum dapat diberantas, bahkan diperkirakan jumlahpenderita TB terus meningkat.
Di kota Samarinda kasus penyakit Tuberkulosis pada tahun 2012 mengalami peningkatan dari tahun-tahun sebelumnya. Berdasarkan angka konversi yaitu angka yang mengukur jumlah pasien TB yang menjadi negatif pada pengobatan fase intensif (atau pada bulan kedua pengobatan) di Samarinda pada tahun 2012 mencapai 320 kasus dari jumlah total 490 kasus. Ini artinya angka konversi di samarinda tahun 2012 hanya mencapai $78 \%$, dan masih di bawah target nasional sebesar 80\%.Angka keberhasilan pengobatan tahun 2012 diukur berdasarkan data pasien yang ditemukan pada tahun 2011 dan dilaporkan hasil akhir pengobatannya sebagai kasus sembuh dan pengobatan lengkap. Dari jumlah pasien TB BTA positif yang ditemukan dan diobati pada tahun 2011 sebesar 490 kasus, yang berhasil disembuhkan dan mendapatkan pengobatan lengkap sebesar $84 \%$ atau 307 kasus. Angka ini juga masih belum mencapai target nasional $>85 \%$.

\section{METODE PENELITIAN}

\begin{abstract}
Alat dan Bahan
Alat penelitian adalah kuisioner dan bahan penelitian merupakan rekam medis pasien.
\end{abstract}

\section{Populasi dan Sampel Penelitian}

Populasi penelitian ini adalah seluruh pasien penderita TB yang menjalani pengobatan di Puskesmas Temindung Samarinda pada periode Maret-April 2014. Serta pasien yang masuk dalam kriteria inklusi yaitu pasien yang rutin menjalani pengobatan, memilki data rekam medis yang lengkap serta bersedia menjadi sampel penelitian, dan kriteria eksklusi merupakan pasien yang baru menjalani pengobatan kurang dari satu bulan. 


\section{Teknik Pengumpulan Data}

Penelitian ini dilakukan dengan menggunakan pendekatan prospektif dengan sumber data penelitian berupa data primer dan data sekunder. Sumber data primer adalah data hasil wawancara dengan pasien dan melalui pemberian kuisioner sedangkan data sekunder dalam penelitian ini adalah data rekam medik pasien Tuberkulosis. Pengumpulan data dilakukan dengan mencatat data berupa karakteristik pasien yaitu usia, jenis kelamin, dan tingkatpendidikan, sertadianalisis kejadian DRPs kategori interaksi obat dan kepatuhan pasien. Kepatuhan pasien dilihat dari hasil kuisioner, dimana parameternya berdasarkan ketepatan pasien minum obat, sedangkan interaksi obat ditinjau dari potensi interaksi secara teoritis antara OAT (Obat Antituberkulosis) dengan obat lain yang dikonsumsi pasien tuberkulosis.

\section{HASIL DAN PEMBAHASAN}

Karakteristik Pasien Tuberkulosis di Puskesmas Temindung Samarinda

Penelitian ini meliputi 22 subyek yang terdiri dari laki-laki dan perempuan. Pengambilan sampel dilakukan dengan kriteria inklusi dan merupakan pasien yang masih menjalani perawatan pada periode Maret-April 2014.Data mengenai karakteristik penderita TB berdasarkan jenis kelamin terdapat pada Gambar 1, karakteristik pasien berdasarkan usia dapat dilihat pada Gambar 2 dan karakteristik pasien berdasarkan tingkat pendidikan terakhir dapat dilihat pada Gambar 3.

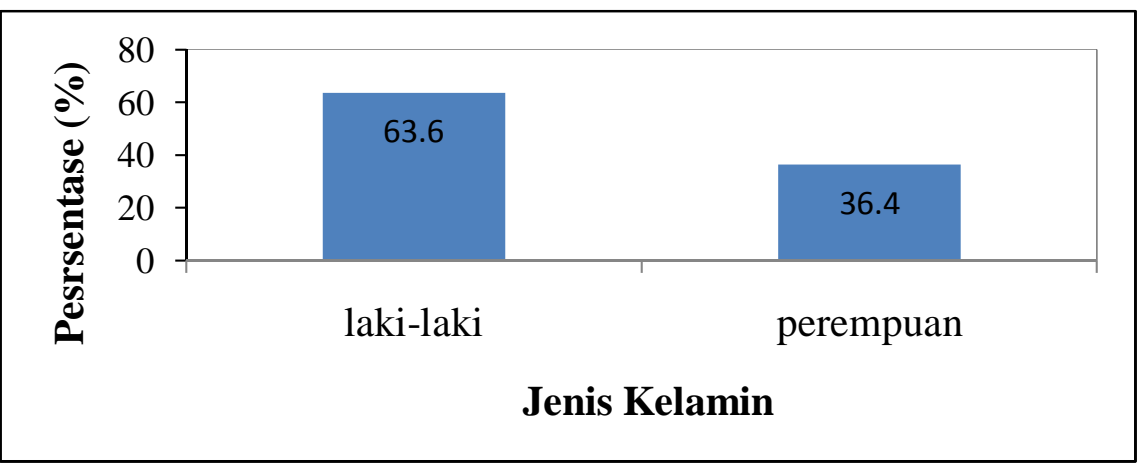

Gambar 1 Distribusi Pasien Tuberkulosis berdasarkan Jenis Kelamin

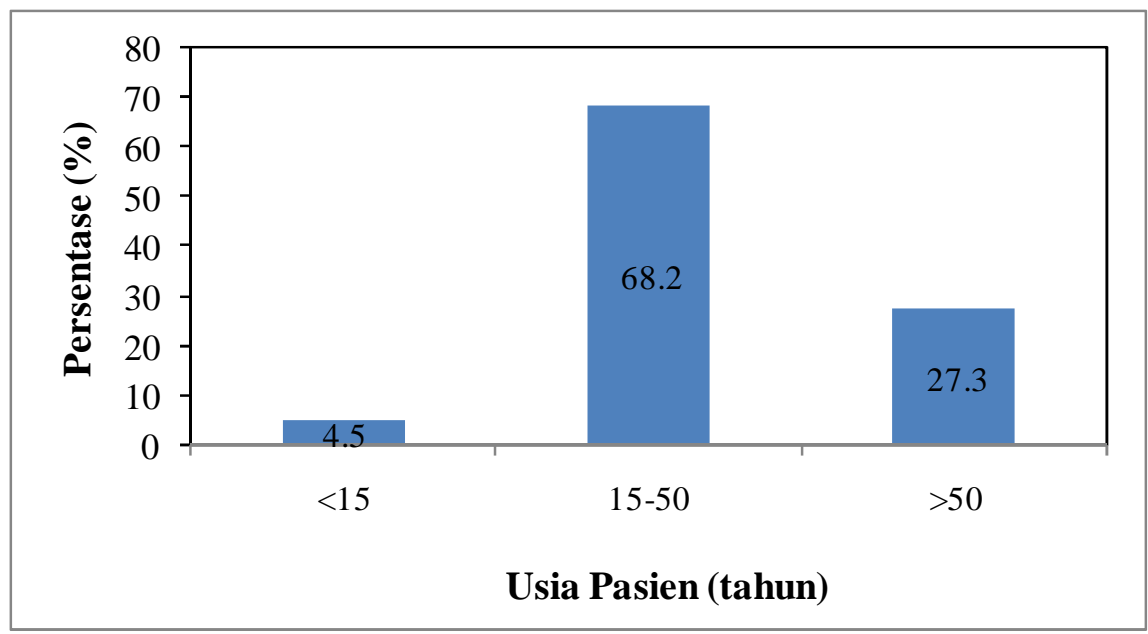

Gambar 2 Distribusi Pasien Tuberkulosis berdasarkan Usia 


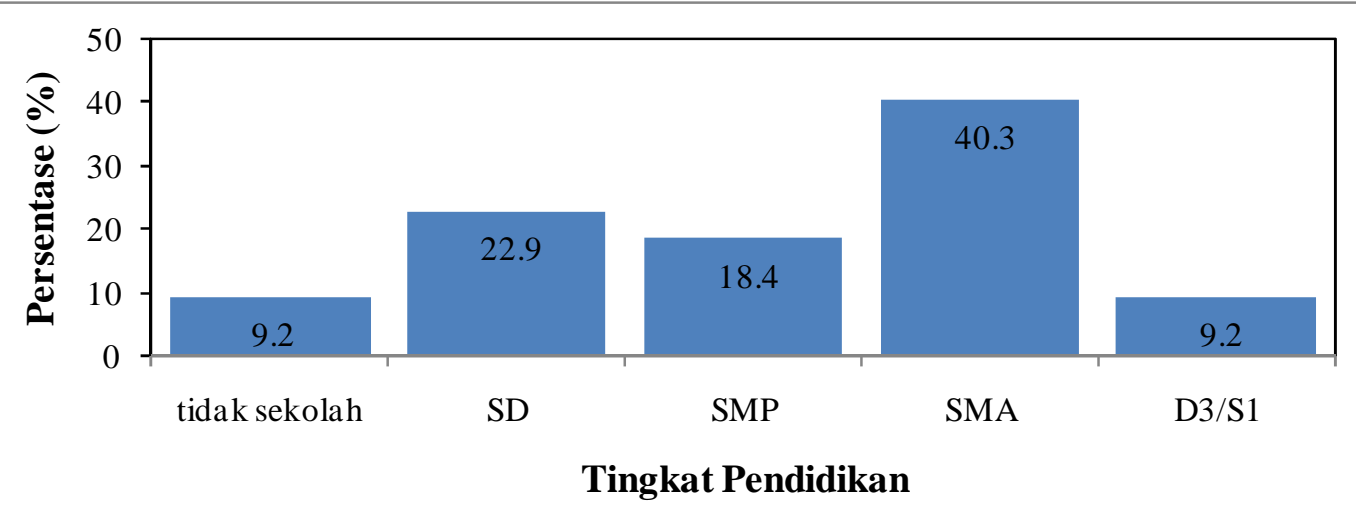

Gambar 3 Distribusi Pasien Tuberkulosis berdasarkan Tingkat Pendidikan

Dari hasil penelitian menunjukkan bahwa penderita Tuberkulosis dengan jenis kelamin laki-laki lebih banyak dibanding perempuan.Tidak ada penjelasan pasti pengaruh jenis kelamin terhadap angka Tuberkulosis yang terjadi.Namun hal ini dapat dihubungkan dengan pria yang cenderung memilki pekerjaan dibanding perempuan yang pada umumnya berstatus sebagai ibu rumah tangga, sehingga pria yang bekerja memiliki lingkungan kerja yang kemungkinan dapat menjadi area penularan baginya.Hasil penelitian ini juga menunjukkan bahwa pasien yang berusia sekitar 15-50 tahun memilki persentase yang paling besar.Hasil penelitian ini sesuai dengan Pedoman Nasional Pengendalian Tuberkulosis 2011, bahwa sekitar 75\% pasien TB adalah kelompok usia yang paling produktif secara ekonomis (15-50 tahun). Pada umumnya kuman Tuberkulosis masuk melalui saluran napas dan bersarang di jaringan paru pada usia dini tanpa menimbulkan infeksi. Pertahanan pasien mungkin berhasil menahan infeksi selama masa kanak-kanak, tetapi turunnya daya tahan tubuh pasien (misalnya karena malnutrisi, kehamilan, proses kelahiran, penyakit-penyakit lain yang dapat menurunkan imunitas tubuh, serta lingkungan sosial orang dewasa yang cenderung menimbulkan resiko penularan baginya) dapat menyebabkan
TB menjadi aktif dan menyebabkan penyakit.

Persentase tingkat pendidikan yang tertinggi adalah lulus SMA.Dalam penelitian ini pasien dengan lulusan SMA lebih banyak memilki pekerjaan menjadi pegawai perusahaan yangcenderung memiliki lingkungan yang lembab dan waktu kerja yang lebih lama atau pekerjaan yang menuntutnya berinteraksi dengan banyak orang, sehingga individu dengan kondisi seperti ini mendapatkan risiko yang lebih besar utuk tertular kuman TB.Persentase pasien S1/D3 yang rendah kemungkinan dapat disebabkan individu yang memilki pendidikan yang tinggi cenderung memilki pengetahuan tentang kesehatan yang tinggi pula, oleh karena itu mereka lebih memilih berobat di rumah sakit atau klinik yang memilki tingkat pelayanan dan fasilitas kesehatan yang lebih baik.Dari hasil penelitian dapat dilihat bahwa 50\% lebih subyek tidak lulus SMA.

\section{DRUG RELATED PROBLEMS (DRPs)}

\section{Interaksi Obat}

Interaksi obat didefinisikan sebagai modifikasi afek satu obat akibat obat lain yang diberikan pada awalnya atau diberikan bersamaan, atau bila dua atau lebih obat berinteraksi sedemikian rupa sehingga keefektifan atau toksisitas satu obat atau lebih berubah. Pemilihan 
obat yang tepat tanpa adanya interaksi obat memilki peranan penting dalam keberhasilan terapi.Akibat pemilihan obat yang tidak tepat bukan saja terjadinya kegagalan terapi, melainkan juga dapat menyebabkan penyakit baru akibat adanya interaksi sesama obat yang digunakan.Sehingga, penting dilakukannya analisis DRPs interaksi obat untuk menghindari kerugiankerugian tersebut.

Penelitian ini menganalisis pemberian obat yang berpotensi untuk terjadinya interaksi obat secara teoritis. Interaksi yang diamati dibatasi hanya berdasarkan interaksi antara OAT dan obat lain yang digunakan pasien untuk mengobati penyakit penyerta. Dari 22 subyek, terdapat 6 subyek yang memilki penyakit penyerta dan diobati, dan terdapat 5 jenis obat yang digunakan selain OAT.5 jenis obat tersebut antara lain glibenklamid, metformin, amaril, allopurinol, parasetamol.

Kejadian DRPs mengenai interaksi obat dapat dilihat dari Tabel 1.

Tabel 1. Kejadian DRPs kategori tepat obat pasien Tuberkulosis

\begin{tabular}{lllc}
\hline No. & \multicolumn{1}{c}{ Jenis OAT } & \multicolumn{1}{c}{ Jenis Obat } & Jumlah kasus \\
\hline 1. & Rifampisin & Glibenklamid & 4 \\
2. & Rifampisin & Amaril & 1 \\
3. & Pirazinamid & Allopurinol & 1 \\
\hline \multicolumn{2}{c}{ Total } & 6 \\
\hline
\end{tabular}

Berdasarkan Tabel 1.dari total 12 kali pemberian obat, terdapat 6 kasus obat yang dinilai secara teoritis berpotensi beinteraksi dengan persentase $50 \%$. Rifampisin (salah satu OAT) dapat meningkatkan metabolisme dari golongan sulfonilurea dalam kasus ini adalah glibenkamid dan amaril (glimepiride), sehingga efektifitas sulfonilurea dapat berkurang, hal ini menyebabkan kadar gula darah pasien yang tetap tinggi dan tidak terkontrol. Sehingga tidak tepat jika pasien TB diberikan antidiabetik golongan sulfonilurea. Sebaiknya hal ini dapat diatasi dengan peningkatan dosis sulfonilurea atau pemberian kombinasi dengan obat antidiabetik lain contohnya metformin. Serta dapat dilakukan dengan pemberian insulin selama terapi Tuberkulosis, dan setelah terapi TB selesai insulin dapat dihentikan dan dilanjutkan dengan antidiabetik oral.

Allopurinol tidak tepat digunakan untuk terapi gout pada penderita TB.Karena pirazinamid (sala satu OAT) berinteraksi secara tidak langsung dengan allopurinol. Di dalam tubuh pirazinamid diubah menjadi asam pirazinoat yang dapat meningkatkan kadar asam urat dalam tubuh. Namun asam pirazinoat ini dapat dioksidasi oleh xantinoksidase (XO) menjadi asam 5-hidroksipirazoat sehingga mengurangi kadar asam pirazinoat. Namun, allopurinol yang memilki mekanisme kerja penghambatan XO dengan jalan kompetitif, menyebabkan XO tidak dapat mengoksidasi asam pirazinoat menjadi asam 5-hidroksipirazoat dan menyebabkan kadar asam pirazinoat semakin tinggi dalam tubuh. Oleh karena itu, allopurinol yang pada awalnya diberikan untuk terapi gout menjadi tidak efektif dan menyebabkan keadaan gout itu sendiri semakin parah.

\section{Kepatuhan Pasien}

Kepatuhan pasien merupakan faktor penting dalam keberhasilan terapi Tuberkulosis. Karena terapi ini menyangkut penggunaan antibiotik yang memerlukan kepatuhan tinggi untuk mencegah terjadinya resistensi antibiotik yang dapat menyebabkan kegagalan terapi.Jika terjadi kegagalan terapi maka kuman Mycobacterium Tuberkulosis di 
dalam tubuhnya masih menginfeksi dan dapat bertambah buruk.Hal ini menyebabkan pasien tersebut mengalami sakit yang semakin parah.Walaupun awalnya pasien tersebut merasa adanya perbaikan, namun dengan kuman Mycobacterium Tuberkulosis yang masih bersarang dapat kembali aktif pada kondisi tertentu ke depannya. Hal ini akan menyebabkan pasien perlu menjalani terapi kembali dari awal dan lama terapi yang semakin panjang. Di samping merugikan diri sendiri, penyakit TB yang masih aktif ini dapat meningkatkan resiko penularan yang poten di lingkungannya.

Tingkat kepatuhan pasien dalam penelitian ini dianalisis berdasarkan hasil kuisioner dan ketepatan waktu pasien mengambil obat sesuai jadwal yang ditentukan. Tingkat kepatuhan pasien akan dibagi dalam 2 kategori, yaitu kategori mandiri dan kategori non mandiri. Dimana kategori mandiri merupakan pasien yang rutin minum obat tanpa bantuan PMO (Pengawas Menelan Obat), sedangkan kategori non mandiri merupakan pasien yang rutin minum obat dengan bantuan PMO (Pengawas Menelan Obat).Sedangkan pasien yang tidak patuh adalah pasien yang pernah melewatkan minum obat dan tidak rutin mengambil obat di puskesmas.

Tingkat kepatuhan pasien penderita Tuberkulosis di Puskesmas Temindung dapat dilihat di Gambar4.

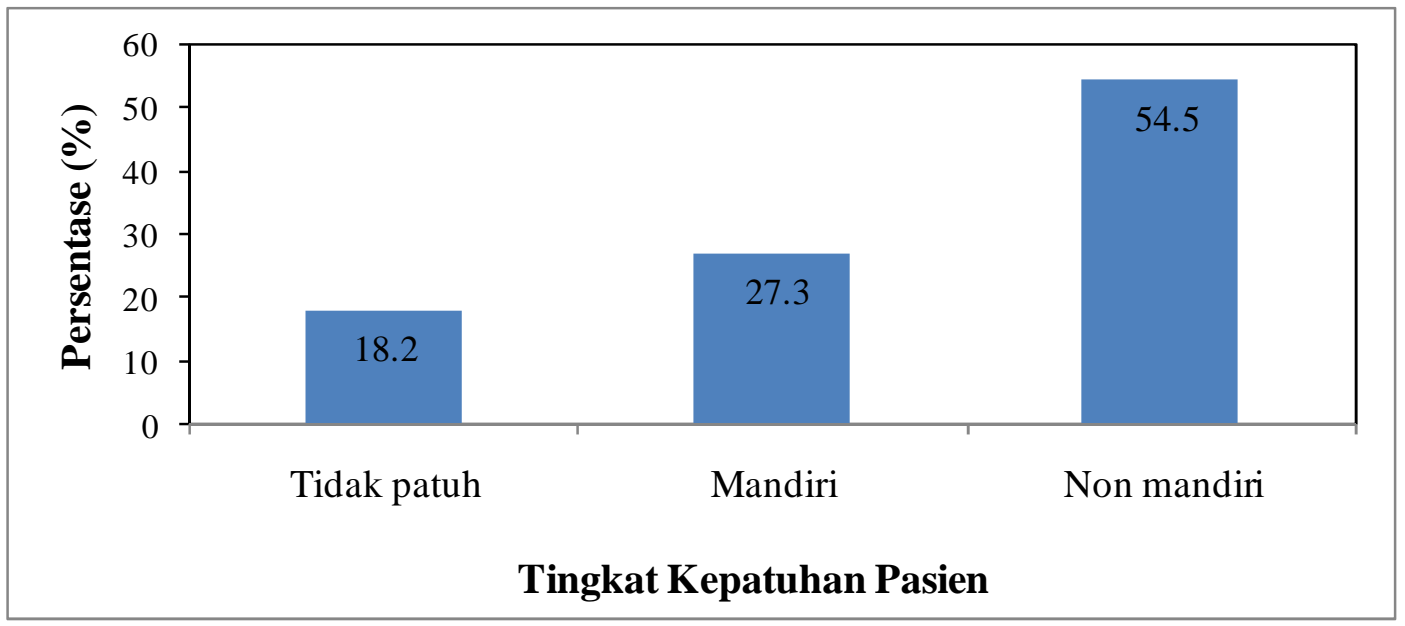

Gambar 4 Distribusi Tingkat Kepatuhan Pasien

Berdasarkan Gambar 4 persentase paling besar adalah pasien patuh yang non mandiri atau pasien patuh yang membutuhkan peran PMO (54,5\%). Dari hasil penelitian, 3 dari 4 pasien yang tidak patuh merupakan pasien yang tidak memiliki PMO, sehingga tidak ada orang lain yang membantu mengingatkan untuk minum obat secara rutin, hal ini menyebabkan mereka lebih beresiko untuk melewatkan minum obat, dan satu pasien lainnya menjadi tidak patuh karena pernah melewatkan minum obat ketika bepergian, dimana tidak didampingi oleh PMO-nya. Hal ini menunjukkan masih pentingnya PMO untuk terus mengawasi dan meningkatkan kesadaran pasien dalam menjalani pengobatannya, sehingga tingkat kepatuhan pasien akan semakin meningkat. Meningkatnya kepatuhan pasien berpengaruh terhadap tingkat kesembuhan pasien. Karena, dalam pengobatan Tuberkulosis kepatuhan pasien merupakan faktor yang sangat penting, mengingat pengobatannya yang menggunakan antibiotik yang memerlukan kepatuhan tinggi untuk 
mencegah terjadinya resistensi antibiotik yang dapat menyebabkan kegagalan terapi.

\section{KESIMPULAN}

Gambaran karakteristik pasien penderita Tuberkulosis di Puskesmas Temindung periode Maret-April 2014 diperoleh pasien dengan jenis kelamin laki-laki $63,6 \%$ dan perempuan $36,4 \%$. Pasien dengan usia $<15$ tahun $4,5 \%$, usia antara 15-50 tahun 68,2\% dan usia > 50 tahun 27,3\%. Berdasarkan tingkat pendidikan pasien, tidak sekolah $9,1 \%$, lulus SD 22,7\%, lulus SMP 18,2\%, lulus SMA $40,1 \%$ dan sarjana $9,1 \%$. Kejadian DRPs mengenai interaksi obat $50 \%$. Tingkat kepatuhan pasien Tuberkulosis di Puskesmas Temindung $81,8 \%$ pasien patuh dan $18,2 \%$ pasien tidak patuh.

\section{UCAPAN TERIMA KASIH}

Penulis menyampaikan ucapan terima kasih kepada pimpinan Puskesmas Temindung Samarinda, dr. Taufansyah selaku pembimbing lapangan penulis serta Bpk. Syarifuddin dan Ibu Tri selaku petugas puskesmas poli paru yang telah membimbing penulis selama penelitian.

\section{DAFTAR PUSTAKA}

1. DepKes RI. 2005. Pharmaceutical Care untuk Penyakit Tuberkulosis. Direktorat Bina Farmasi Komunitas dan Klinik Ditjen Bina Kefarmasian dan Alat Kesehatan, Departemen Kesehatan: Jakarta

2. Surya, Asik, dkk. 2011. Pedoman Nasional Pengendalian Tuberkulosis. Kementerian Kesehatan Republik Indonesia: Jakarta 